\title{
Chronic human brucellosis with pancytopenia in a young girl from a camp for Internally Displaced Persons
}

\author{
Thamotheram S, Thirumavalavan $\mathrm{K}$ \\ Colombo North Teaching Hospital, Ragama, Sri Lanka \\ Correspondence: Dr. S. Thamotheram (sthamotheram@yahoo.com)
}

\section{Case Report}

A 19-year old girl was transferred to our hospital from Base hospital Vavuniya in June 2009 for investigation and management of abdominal distention. She lived in a camp for the Internally Displaced People (IDP) in Mannar and had developed a low grade fever and abdominal distention for one month duration. Apart from mild fatigue, there were no other significant symptoms. She had consumed unpasteurised cow's milk in the war area. She had no past history or a contact history of tuberculosis.

On examination she was pale, anicteric, afebrile and had no lymphadenopathy. She had non-tender mild splenomegaly but liver was not palpable. Her respiratory, cardiovascular and neurological systems were clinically normal. Her $\mathrm{Hb}$ was $7.6 \mathrm{~g} / \mathrm{dL}$ while White cell and platelet counts were $2.0 \times 10^{9} / \mathrm{L}$ and $25 \times 10^{9} / \mathrm{L}$, respectively. Blood picture showed pancytopenia and possible iron deficiency anaemia. Her initial ESR was $45 \mathrm{~mm}$. Serum AST and ALT were 41 and $30 \mathrm{U} / \mathrm{L}$, respectively, while INR was 1.49. Renal functions were normal but CRP was repeatedly elevated. Serum protein electrophoresis showed normal albumin band with polyclonal increase in $\gamma$ globulin. Abdominal ultrasonography showed splenomegaly with multiple echogenic spots in both spleen and liver. Bone marrow biopsy showed no evidence of haematological or nonhaematological malignancy and marrow iron stores were completely depleted. Her liver biopsy showed focal nodular hyperplasia but no granulomas were detected.

At this stage, the possibility of either chronic disseminated TB or chronic brucellosis was considered. Bone marrow culture for mycobacterium tuberculosis was negative and PCR for TB was negative. However brucella PCR was positive for 10 copies.
Contrast CT abdomen revealed focal nodular hyperplasia (a benign condition seen in females) in the right lobe of the liver with multiple hyper-echoic lesions. With the history of consumption of unpasteurised cow's milk and positive PCR for brucella we confirmed the diagnosis of chronic brucellosis associated with bone marrow suppression causing pancytopenia.

She was started on the combination of oral ciprofloxacin $500 \mathrm{mg}$ bid and doxycycline $100 \mathrm{mg}$ bid for 6 weeks. Haematinics were given to replenish iron stores. At the end of treatment she was asymptomatic and her blood count returned to normal.

\section{Discussion}

Brucellosis is a chronic granulomatous zoonotic infection which can affect every organ of the human body. Among the four species found, a vast majority is caused by B.melitensis (1). It is transmitted to human by consumption of unpasteurised animal milk products and as an occupational disease in shepherds, veterinarians and dairy-industry professionals. Brucella species have a unique ability of invading both phagocytic and non-phagocytic cells and surviving in the intracellular environment by avoiding the immune system in different ways, explaining why brucellosis is a systemic disease and can involve almost every organ (2). Our patient has consumed unpasteurised cow's milk during the war and developed brucellosis complicated by pancytopenia. The frequency of pancytopenia ranges from $3 \%$ to $20 \%$ (3). Hematological abnormalities usually resolve promptly with treatment of the primary disease (3). Pancytopenia could be due to hypersplenism, bone marrow involvement, haemophagocytosis or immune-mediated cell destruction $(4,5)$. The gold standard for diagnosing 
brucellosis is bone marrow culture which is difficult in Sri Lanka. PCR is fast, could be done in any body tissue and becomes positive after 10 days of inoculation (1). Our patient was successfully treated with the combination of oral ciprofloxacin and doxycycline for 6 weeks.

Keeping in mind the possibility of brucellosis in people who are living in temporary camps, mainly in the North, East provinces in Sri Lanka, health care workers should be more alert on early diagnosis and treatment of brucellosis to prevent further spreading.

\section{References}

1. Georgios P, Nikolaos A, Mike B, Epameinondas T. New England Journal of Medicine 2005; 352: 2325-36.
2. Wafa Al-Nassir, Michelle V Lisgaris, Robert A Salata. Infectious Disease Brucellosis eMedicine from WebMed 2009; Feb 03, online article.

3. İlyas Tuncer, Hayrettin Akdeniz1, İsmail Uygan, Kürşad Türkdoğan, Saliha Çekici, Ahmet Durmuş Yüzüncü Yı1. A brucellosis case with ascites, hearing loss and pancytopenia The Turkish Journal of Gastroenterology 2002; 13: 168-71.

4. Young EJ, Tarry A, Genta RM, Ayden N, Gotuzzo E. Thrombocytopenic purpura associated with brucellosis: report of two cases and literature review. Clinical Infectious Disease 2000; 31: 904-9.

5. Pappas G, Busilkovski M, Christon L, Tsignos E. Immune Thrombocytopenia attributed to brucellosis and other mechanisms of brucella induced thrombocytopenia. American Journal of Haematology 2004; 75: 139-41. 